\title{
A CONCEPTUAL FRAMEWORK FOR MANAGING RELATIONSHIPS BETWEEN ALL PARTICIPANTS DURING IT SERVICE AND SUPPORT ACTIVITIES
}

\author{
A.C. Leonard \\ Department of Informatics \\ University of Pretoria \\ aleonard@hakuna.up.ac.za
}

\begin{abstract}
Since the early days of computing, IT professionals have been struggling with their end users (customers) to such an extent that end users became sceptic about the quality of service and support IT professionals can offer. As such, relationships between IT professionals and end users were in many cases very poor, which impacts negatively on the efforts to use information technology to the advantage of organizations or communities as a whole. This paper briefly describes the historical reasons therefor and gives a theoretical foundation for the establishment of IT-end user relationships. The paper describes IT-end user relationships as intriguing and complex and proposes a conceptual framework that explains all the important elements involved during the establishment and maintenance of sound relationships as well as for managing change. This paper is based on a research study conducted into the working relationship between IT departments and its end users. The research was done by means of a qualitative approach in which thought experiments were used to inductively refine the results of the research study.
\end{abstract}

\section{OPSOMMING}

Sedert die ontstaan van die rekenaarwese en die gepaardgaande dienslewering via inligtingstegnologie bestaan die neiging by eindpuntgebruikers om skepties te staan teenoor die gehalte van diens wat deur inligtingstegnoloë gebied kan word. Dit het daartoe gelei dat die verhoudinge tussen eindpuntgebruikers en die inligtingstegnoloë vertroebel is. Voordelige gebruik van inligtingstegnologie deur ondernemings en die gemeenskap is gevolglik daardeur benadeel. Hierdie stuk behandel kortliks die historiese oorsake vir die toedrag van sake. Dit beskryf ook die teoretiese grondslae vir die skepping van wedersydse verhoudings vir die probleemsituasie. Die stuk ondersoek die aandagwekkende en komplekse verhoudingsmilieu. Dit beskryf vervolgens 'n voorgestelde konsepraamwerk waarmee die belangrik elemente by die daarstelling en instandhouding van gesonde verhoudings blootgelê kan word. Dit behandel ook die gepaardgaande begrip van veranderingsbestuur. Die navorsing is gebaseer op werklike praktykgegewens. Die navorsings maak gebruik van kwalitatiewe metodes en induksie om die resultate tot bruikbaarheid te verfyn. 


\section{INTRODUCTION}

In order to overcome the problem of poor relationships between IT professionals and end users, it is argued that a "human-behaviour" strategy of some kind should be followed. This strategy should involve amongst other things focusing on those social issues that will enhance trust, commitment, co-operation etc. Reich \& Benbasit [19] point out that there are two dimensions to strategy creation: the intellectual dimension and the social dimension. Research into the intellectual dimension is more likely to concentrate on the contents of plans and on planning methodologies. Research into the social dimension is more likely to focus on the people involved in the creation of cooperation and mutual understanding. The social dimension of alignment is defined as "the state in which business and IT executives within an organizational unit understand and are committed to the business and IT mission, objectives, and plans". The same argument is true for participants of a software project. To ensure that service and support of a high quality is offered to the organization, IT professionals and end users should understand each other and should be committed to the software project they are working on.

Another theoretical perspective supporting the concept of the social dimension is the social construction of reality. This view would suggest that, in addition to studying artifacts (such as plans and structures) to predict the presence or absence of alignment, one should investigate the contents of the players' minds: their beliefs, attitudes and understanding of these artifacts (Reich \& Benbasit [19]).

This paper focuses on the social dimension in terms of identifying those elements that are necessary for the establishment and maintenance of sound IT-end user relationships.

Research in this field has shown that relationships between IT professionals and their end users are intriguing and complex [1]. The objectives of the research were, amongst other things, to identify and describe the most important soft issues, which will enhance a supportive culture - "which will make it easier for developers to work together" (Sawyer et al (1996)). Furthermore the research was aimed at creating a better understanding of the social nature and characteristics of relationships between end users and IT professionals while IT is performing its duty as service and support agent.

Theories of how relationships between an IT department and its end users should be managed are scarce. Those that do address issues in this regard (Wike et al. [24]; CSC research foundation [7] ; Beard \& Peterson [1] ) do not look into soft issues, or give substance to the contents of such relationships.

The paper gives a brief background of the cause and nature of poor relationships between IT professionals and their end users, and as such between team members of software projects. In the second part of the paper the nature of and theory behind IT-end user relationships are examined. Thereafter a conceptual framework is introduced in two parts. The first conceptual framework shows all elements and their relationship under circumstances where no change is involved, whereas the second and final conceptual framework takes change into consideration. 


\section{A BRIEF HISTORY OF POOR RELATIONSHIPS}

Umbaugh [22] states in his argumentation of organizational imbalances that too often IT exists as an adjunct to the organization and not as an integral part of the whole. This situation unfortunately still exists today and contributes to the so-called culture gap between IT departments and their end users. Du Plooy [10] explains this gap as follows:

“...the 'culture gap' should be understood as a gap of misunderstanding in the sense of two different organizational 'cultures' that, according to Grindley, coexist in most organizations. The two cultures under discussion here are the 'culture' of the IT profession and the 'culture' of the rest of the organization."

Historically the gap was caused mainly by the difference in management culture, as well as human behaviour problems on both sides. The culture of both the IT department and the business is also an important obstacle in building mutual trust, and eventually in building sound relationships between IT and its end user environment, and as such in creating alignment between IT and the business. According to Moad [15], the IT professional has been fighting for recognition and relevance at the CEO level for the last twenty-five years. He gives many examples illustrating the kind of culture that exists, which could be described as the main reason for misunderstandings and misconceptions about IT amongst today's end users.

When a user initially gets involved with the IT department, he/she is introduced to one or more IT professionals who will specifically deal with his/her problem(s). Normally a sense of mutual understanding and trust grows out of this relationship, which will definitely get disturbed the moment elements of such a relationship change without the knowledge or approval of the role players. In practice end users very seldom get involved in the management of change which will influence a relationship in which they are involved, or even get properly informed of changes that take place on the IT side. Practice has indicated that this is a typical reason for distrust and criticism against IT departments from the end user environment.

A review of literature on the history of relations between end users and their IT departments in the IT industry and how they were treated, tells a very sad tale. The attitude or behaviour of IT departments or the so-called DP professionals was one of "we know the best", or "we know what the end user needs and therefore we don't need to try and get the end user involved". Furthermore, many people on the business-side of an organization have never been exposed to computer technology and are virtually computer illiterate, which makes them uncertain and in many cases the "prey" of an IT department. As a result of this attitude few attempts were made to keep communication with the end user on a sound basis while developing a system.

Although many efforts were made in the past to address these issues, the emphasis mainly fell on putting structures and procedures together in order to get out of the end user what his basic needs are. Thereafter the IT department normally followed a lonely journey through the last phases of the systems development life cycle. 


\section{THE DEFINITION AND CHARACTERISTICS OF IT-END USER RELATIONSHIPS}

\section{Definition of IT-end user relationships}

According to Leonard [14] an IT-end user relationship consists of two dimensions, namely, a physical dimension and an abstract dimension. The physical dimension describes those elements that are necessary in order to enable contact between IT and its end users, whereas the abstract dimension describes the soft issues of a relationship. These two dimensions enable one to describe the holistic nature of such a relationship fully and to encapsulate the important elements of a support-oriented organization, namely mutuality, belonging, and connection, as mentioned by Pheysey [18] in her book Organizational Cultures. The basic components of such a relationship are illustrated in Figure 1.

In the rest of this section the paper focuses on describing the most important characteristics of the physical and abstract dimensions. This will give the reader enough understanding of the social nature of IT-end user relationships.

\section{Physical elements}

As far as the physical dimension is concerned, the following elements could be seen as the most important:

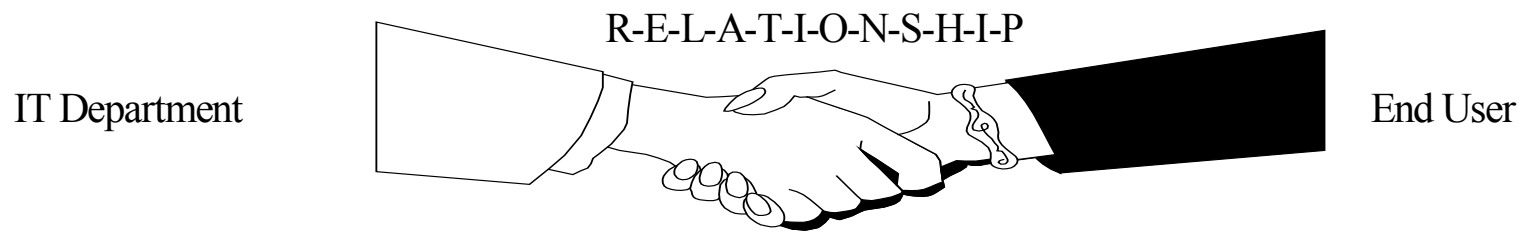

\begin{tabular}{|c|c|c|}
\hline Physical dimension & \multicolumn{2}{|c|}{ Abstract dimension } \\
\hline People & Dynamic & $\begin{array}{l}\text { Sensitive } \\
\text { to change }\end{array}$ \\
\hline Technology & $\begin{array}{l}\text { Knowledge } \\
\text { base }\end{array}$ & $\begin{array}{l}\text { Suppotive } \\
\text { culture }\end{array}$ \\
\hline Procedures & Holistic nature & Co-operation \\
\hline Structures & Commitment & Sustainability \\
\hline
\end{tabular}

Figure 1: The basic components of an IT-end user relationship (Leonard (1998)) 
- People ${ }^{1}$ : A relationship consists of all the responsible people who are involved in the systems development life cycle at a given time. "Responsibilities are negotiated and shared between systems developers and users" (Dahlbom \& Mathiassen [8] ).

- Technology: Technology may be seen as one of the most important elements in such a relationship, enabling the people who participate in the relationship to communicate with one another. The importance of proper communication structures, both vertically and horizontally, are emphasized by Bommer et al. [2] and could be seen as one of the most important organizational characteristics associated with unethical activity. Apart from the normal communication technology, facilities like help desks and Internet are of the most important factors in this regard.

- Procedures: Two types of procedures are of importance, namely organizational procedures (such as standards and policies) which already exist and which can be seen as a given, and new procedures that are being created by people because of their interaction with the given procedures and technology (DeSanctis \& Poole [9] ).

- Structures: Depending upon the "type" of end user, and therefore the service and support that will be offered, relationships will differ in content as far as formal and informal social communication structures are concerned. The most common of these structures are project meetings, JAD sessions and end user group meetings.

\section{Abstract elements}

As far as the abstract dimension is concerned, the following elements are the most important:

- They are dynamic: The nature of the relationships between the IT department and its end users will, amongst other things, depend upon the type of end user, as well as upon regarding the end user as a human being. According to Stokes [22], when talking to end users, the IT professional should always bear in mind their concerns, problems, environment, and responsibilities in terms of opportunities for IT services and support. Furthermore, he says, continuous contact with end users gives IT the opportunity to gain more insight into their problems.

- They are sensitive to change: Because of the social nature of relationships, any form of change initiated on either the IT or the end user side may disturb a relationship. It is argued that any kind of change having an effect on any of the elements of either the physical or abstract dimensions of a relationship will in fact disturb the relationship because of its holistic nature, which will be described later.

- They have a knowledge base: According to Beard and Peterson (supra) at least part of the design problem seems to be that the analyst/designer is working from his or her own perceptions of the user's needs, which often include unrealistic expectations of user knowledge and an often mistaken idea of user desires and requirements. Furthermore, he says, the analyst views the computer from an expert's point of view and often a technical perspective. The user views the computer as a potentially useful tool, but from a more 
general orientation. These two views are quite different and are often incompatible and in conflict.

Newcomb [16] has explained this type of relationship in the early 1960 s as the coorientation model. According to his model, if an object (the computer) is important to us, we expect others to whom we are attracted or with whom we interact also to like the object and view it from our perspective. A "strain toward symmetry", an attempt to reach a common understanding or viewpoint, can develop from the discrepancies between the two possibly different orientations. The resolution of these different perspectives is possible only when the analyst begins to understand the needs, requirements, and desires of the user in order to design and produce the system properly. Users must also aid in this resolution by understanding the limitations of the computer systems they desire, as well as by developing a thorough and specific understanding of their own needs.

The abovementioned explanation of the complex world of perceptions, attitudes and approaches towards developing software products by IT professionals for the end user, forces us to a point where one can say that in order to overcome the most serious problems during this communication process in a relationship, a knowledge base of some kind is necessary before entering a relationship.

- They have a supportive culture: In order for a relationship to be sound, continuous support and mutual understanding, amongst other things, need to be elements of such a relationship. According to Pheysey, a support-oriented organization has the elements of mutuality, belonging, and connection. Furthermore, an appreciative form of control should be applied, which means: "management is seen to be a process focused on maintaining balance in a field of relationships" (Gadalla and Cooper (1978), quoted by Pheysey).

- A co-operative behaviour pattern is followed by the participants: Co-operation is not a fixed pattern of behaviour, but a changing, adaptive process directed to future results. The representation and understanding of intent by every party is therefore essential to cooperation, and as such emphasizes the importance of communication during co-operation (Clarke \& Smyth [6] ).

Co-operation can also create new motives, attitudes, values and capabilities in the cooperating parties, which will help create and maintain a supportive culture.

- They have an holistic nature: The important elements making up a relationship between the IT department and its end users at a given time should be organized together as a whole. If any of these elements are disturbed in a negative sense, the whole relationship between the IT department and its end users is undermined. In other words, the relationship as a whole is more than the sum of its elements and therefore one can say that it has an holistic nature.

- Sustainability: A most obvious characteristic of the abstract dimension is its sustainability over a period of time. In this regard time refers to the life span of an IT-end user relationship. One can therefore argue that from an information systems viewpoint, a relationship of this kind will only last until the product or service reaches the end of its life cycle. 
In this regard Introna [11] states: "Structures as relationships are contingent, it appears and disappears. It could be brief (a few seconds) or long lasting (several years)."

- Commitment: Kinlaw [13] states that one of the primary tasks of a manager is to create commitment and focus in employees. He furthermore states that managers who help employees increase their knowledge, skill and experience also are building employee commitment. In this regard it is important that managers should take note of the four sturdy supports of commitment, namely: (a) clarity of goals and values; (b) employee competencies that ensure success; (c) the degree of influence that employees have; and (d) the expressed appreciation given to employees for their contributions. Commitment should be seen as a solid block that rests on these four supports or legs (Kinlaw [13] ).

Commitment has been defined by Newman \& Sabherwal ( [17], referring to the work of Staw (1982)) as a state of mind that holds people and organizations in the line of behaviour. It encompasses psychological forces that bind an individual to an action. Commitment has been argued to greatly affect the persistence of behaviour (Newman \& Sabherwal ( [17] , referring to the work of Salancik, 1977)).

In terms of IT-end user relationships commitment can be defined as "an agreement between an end user [customer] and a performer [IT specialist], based on a set of conditions of satisfaction within a predefined cycle time." (Welty \& Becerra-Fernandez [23] ).

All the elements described above form important sub-dimensions of the physical and abstract dimensions. Each of these elements plays a specific social role in an IT-end user relationship environment, which impacts on the soundness of a relationship and as such on the cooperation between team members during systems development.

\section{CONCEPTUAL FRAMEWORK FOR IT-END USER RELATIONSHIPS}

In the first part of this section a conceptual framework is discussed in terms of an IT environment where no change is involved. This framework serves as a building block for the final conceptual framework which supports the handling of change.

\section{When no change is involved}

The conceptual framework of IT-end user relationships consists of the following three main components, each of which has sub-components explaining the internal operations of each process:

- relationship initialization process

- relationship activities process

- Feedback and control process.

The summarized conceptual framework is given in figure 2 without all the detail described in the rest of the paper. 


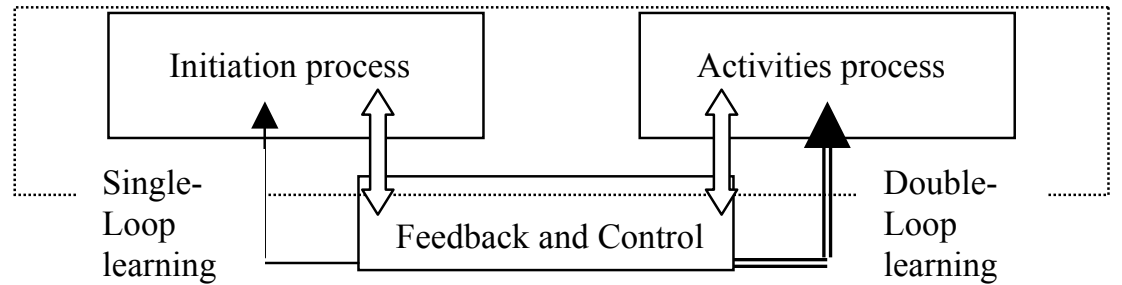

Figure 2: The processes involved in establishing and maintaining sound IT-end user relationships

The conceptual framework with all the detail is illustrated in figure 3. These components present the life cycle of an IT-end user relationship. Furthermore, although each component has a variety of elements (sub-components) that play a role during the life cycle of a relationship, the extent to which each element is involved depends on the IT-end user relationship type as well as the adopted paradigm. The relationship type determines the nature of involvement of end users during service and support activities, while the paradigm determines the fundamental set of assumptions adopted by all participants in such a relationship and will have a direct influence on the soundness and continuity of such a relationship ( $c f$ above).

The initiation process should be seen as the process which takes place when the end user and the IT department start together as parties negotiating the terms and means of giving a specific service or support to the organization. To use the words of Ciborra [4], the parties start with transacting, whereby information is used and produced to determine the basis of the needs of one or more end users. To be more specific, the information is used for the following purposes: it is a means of searching for a potential partner; it signals willingness to exchange; it contains the terms of the contract; it is the medium of control, enforcement and modification of the contract; and it maintains communication during bargaining (Ciborra [4], referring to the work of Barth (1981)).

During the activities process of the relationship three major activities take place which have an impact on or which are affected by the different elements in the physical and abstract dimensions. These activities are:

- assimilation of participants

- service and support

- decision making process.

Although the participants may know one another by this time, they have not yet worked in a team. The purpose of the assimilation process is to allow all team members (as well as newcomers joining the existing team) to go through an orientation process in order to understand the goals, expectations, mission, norms and ground rules (ethical issues) of the project that they are going to work on within the specific IT-end user relationship environment. Kelly [12] calls this process the stages of team development. According to him teams go through a series of 
predictable stages ("forming", "storming", "norming", and "performing") as they develop into maturity. Understanding these stages and helping teams move through them is essential to making teams fully functional. A discussion of these team-building stages falls beyond the scope of this paper.

Feedback and control is a continuous process that gives all participants the opportunity to give their own evaluation (feedback) of how they experience the activities of a specific relationship in which they are involved. "Individuals learn as a result of their experience, and so do organizations." (Robey \& Sales ([20], op. cit.)). Furthermore, it allows participants to have control over the progress of a specific service and support activity (project). In other words, if a relationship was terminated, or if there was a shift from one type of relationship to another, or if one or more participants were removed from a specific IT-end user relationship, all participants involved should give feedback on their experience. Suggestions on how they believe a specific IT-end user relationship or even the conceptual framework in general could be improved should also form part of this ongoing process. In general, the champion in such a relationship as well as the management of the IT department should take cognisance of such feedback.

\section{When change is involved}

Although the management of change in its broad sense falls beyond the scope of this paper, some important issues regarding the construction of the conceptual framework for handling changes need to be discussed.

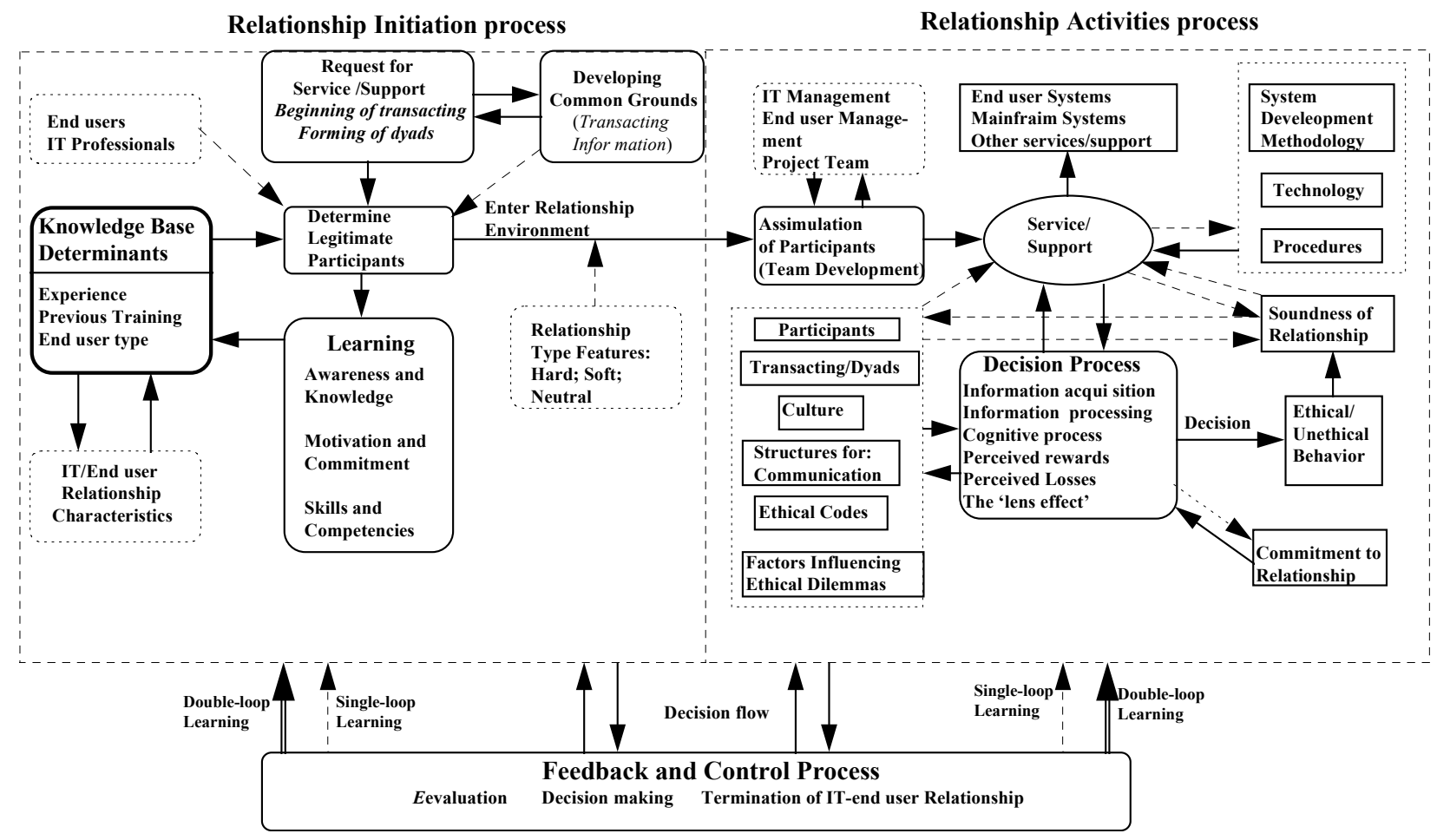

Figure 3: Conceptual framework of IT-end user relationships showing all the soft issues which support cooperation between team members during systems development 
It is important to remind oneself of many situations where IT professionals made changes of some sort without consulting end users at all. This situation has been responsible for the breakdown of many relationships between the IT department and its end users. These changes normally cause unpleasant surprises for the end user and sometimes even for other IT professionals. It is therefore of the utmost importance that changes that might have an influence on any IT-end user relationship should be dealt with in a more profound way. This is sanctioned by Davenport and Short (1990) who describe it as follows:

"It seems that what is lacking is a common view between users and IS. What is needed, is a linking meganism, something to bring IS and users together to deal with rapid change."

Cusack (1993) states, "the answer lies in the approach to people, not the technology. The best high-tech idea can fail due to low-tech or even no-tech reasons". Cusack states that one of the best ways to handle situations of change is to involve people as soon as possible in the decision-making process. In this regard she cites the words of Stokes, Jr. author of Controlling the future: Managing Technology-Driven Change:

"Organizations need to be very, very sure that they help people to understand why change is needed in the first place...People have a right to know what is going on if you want them to be partners in the change"

According to Sprague \& McNurlin [21] change management is the process of assisting people in making major changes in their working environment. Change disrupts people's frame of reference if it represents a future where past experiences do not hold true, says ODR, a change management firm in Atlanta, Georgia (Sprague \& McNurlin [21]). People resist change, especially when they view it as a crisis. They cope by trying to maintain control. In the case of change they do not understand fully or are not prepared to handle, employees may react in several ways. They may deny the change, they may distort information they hear about it, or they may try to convince themselves, and others, that the change(s) will not affect the status quo. These are forms of resistance.

Caperelli (supra) states that with careful planning and two-way communication, chokepoints could be overcome and suggests a management framework with the following basic structure:

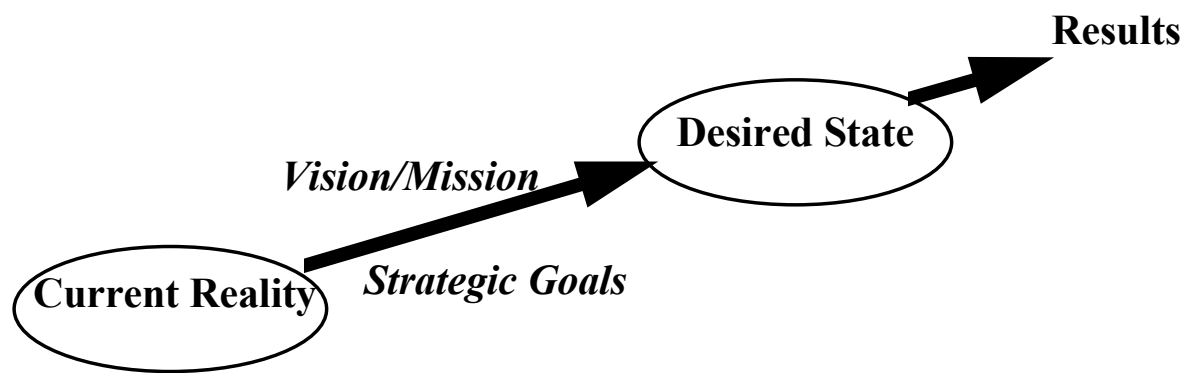

Figure 4: Change framework (Based on the work of Caperelli [3] ) 
Leonard [14] argues that in order to manage change effectively within an IT-end user relationship environment, a transformation process should be used to ensure that all elements (physical as well as abstract elements; cf above) of a specific IT-end user relationship adapt to the new circumstances. The main purpose of the transformation process will be to help ${ }^{2}$ participants within the relationship to adapt to the new change(s) influencing their working relationship. It is of course true that one or more participants could be quite happy (satisfied) with a specific change that affected the specific IT-end user relationship they belong to. These participants can be regarded as having gone through the transformation process without formal help. What is important in such a case is that these participants should take the responsibility to support those who need help as explained below. The principles behind the transformation process are:

- Strengthen the participants' commitment to the project.

- Ensure that the focus of every participant in the relationship, but especially that of the team as a whole, which has been flawed by the change(s), is fixed or adjusted.

"One of the things we mean by 'committed' people is that they have a focus" Kinlaw ( [13], op. cit.)

- Serve as forum for those individuals in a relationship who understand and who has accepted the change to support and motivate other members.

- Support the champion in evaluating whether focus has been adjusted so to continue with the "normal" activities of the team.

A revised summarized framework with all the processes is shown in figure 3. The detailed framework transformation process is illustrated in figure 4 and explained in the rest of the paper.

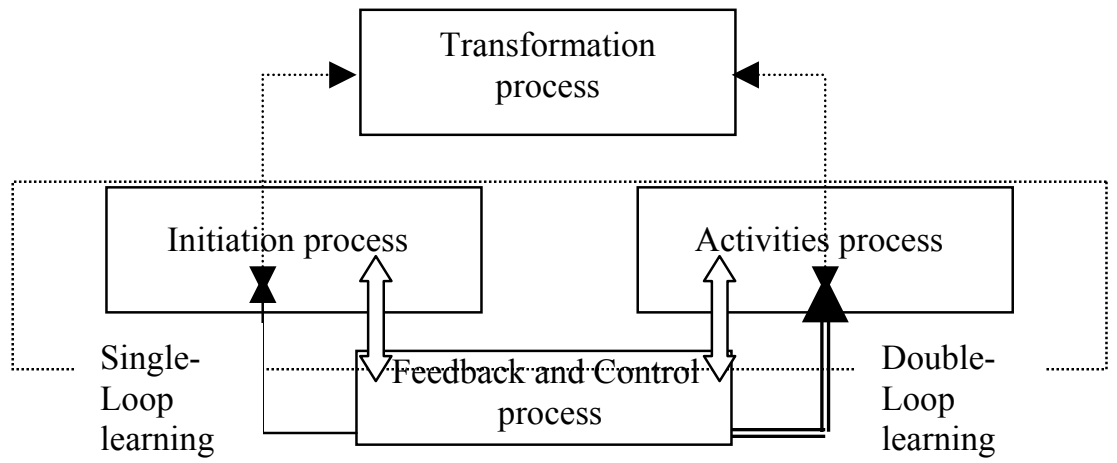

Figure 5: The processes involved in establishing and maintaining sound IT-end user relationships 
This framework illustrates three major components, namely:

\section{- Disrupted relationship}

This component indicates that at least one of the elements in a given IT-end user relationship has been disrupted. These elements form part of the physical or abstract dimensions. The term disrupted is used to indicate that one or more of the elements in a given relationship has undergone certain changes that have a negative impact on the relationship. A poor communication system in a systems development environment could for example impact very negatively on the relations between the different members of a project team to such an extent that one can say that apart from the damage to the physical elements of the relationship several elements of the abstract dimension, like commitment, trust, cooperation, etc., could also be damaged as a result of, for example, a "bug" in the communication system.

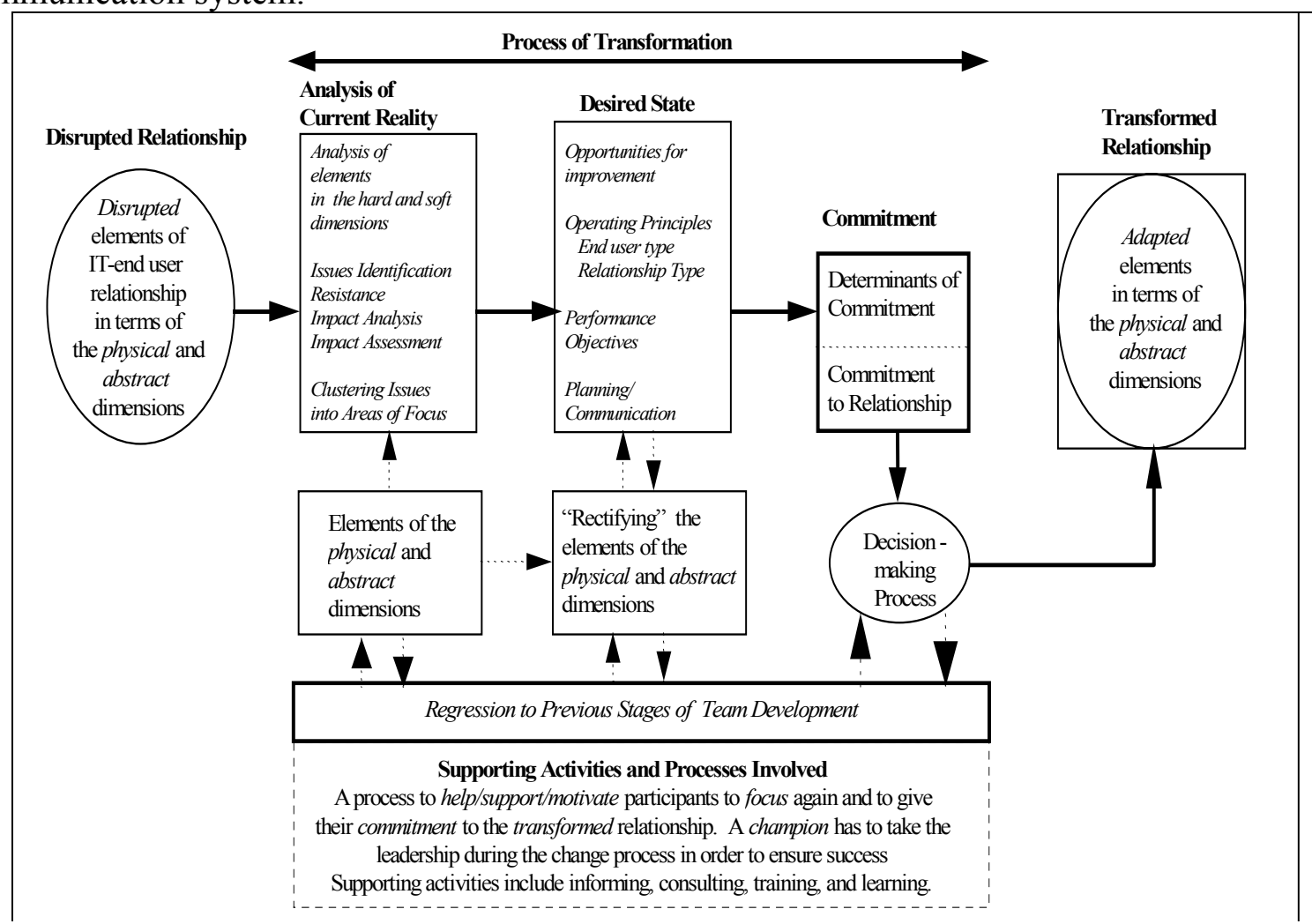

Figure 6: Conceptual framework for the handling of change in an IT-end user relationship environment

\section{- The transformation process}

The purpose of this component is to take all elements of a disrupted IT-end user relationship through a process of transformation. In this regard it is important to realize (as was explained under the previous component), that if a physical element (apart from people) has been disrupted, it is important that the problem should be rectified as part of the transformation process. In other words, it is not only the people element that has to be transformed, but all elements, so as to ensure that the holistic nature of an IT-end user relationship would not have a counter effect on the transformation process. 
In order to ensure that commitment to the relationship is reinstated, Kinlaw [13] states that it is important to give serious attention to the four "supports" of commitment. According to him commitment is not something that we can observe directly. It is argued by Kinlaw that commitment exists because of what people say and do. In this regard he states that there are at least two kinds of behaviour that signal employee commitment. The first is that they appear to be very focused in doing their work, and the second characteristic is their willingness to make personal sacrifices to reach their team's or organization's goals.

The activities involved in the transformation process will of course depend on the nature of the change that occurred, but should consist of the following basic actions:

\section{Analysis of current reality}

It is important to give all role players the necessary opportunity to analyse the new situation in order to become familiar with their new circumstances.

\section{Desired state}

After a proper analysis of the current state, it is important to start working towards the desired state. This could imply that the type of relationship has to change and by implication also the end user type. Furthermore, it is important to focus on performance objectives, as this is normally an aspect that gets damaged by change.

Plans of action should be implemented to do the necessary "transforming". This could include activities like informing, consulting, training, and learning. These activities should help and encourage participants to better understand and cope with the changes. Training could of course take the form of on the job training, especially in the case of new participants. In other words, formal training is not always necessary.

It is of the utmost importance that all participants in an IT-end user relationship (the target) as well as those people who are not directly involved in an IT-end user relationship but who will be affected by any changes, are consulted with by the change agent.

Everybody should be kept informed on a continuous basis about the status of the transformation process, especially if it runs over a long period of time. Last but not least, the transformation process should be regarded as a learning process, not only to ensure that mistakes would not be repeated, but also to improve on similar situations in future.

\section{Commitment}

Much has been said about commitment ( $c f$ above), and the purpose of this activity in the transformation process is to ensure that all participants in the relationship recommit themselves to the relationship before they can continue with normal relationship activities ( $c f$ above). 


\section{Decision-making}

It is the responsibility of all role players in the relationship, and especially that of the champion ( $c f$ above), to ensure that all participants in the relationship take part in decisions. Furthermore, it is the responsibility of the champion to ensure that all participants have recommitted themselves to the relationship before the important decision is made to go on with the normal relationship.

\section{Team development}

In terms of the effects of change it is important to take note of the effect it has on the level of development of any team. Kelly [12] indicates that the moment certain kinds of changes affect a team, it seems that the development level of the team is also affected by this, and therefore the team will have to "rebuild" itself again.

"In many cases, teams will 'regress' to one of the previous stages and work their way back to 'Achievement'."

Kelly ([12], op. cit.)

It is therefore important to give proper attention to the development of the teams during the transformation phase of the change management process of IT-end user relationships, to ensure that the level of team development is maintained.

\section{- Adapted IT-end user relationship}

This component indicates that all the elements as described in the physical and abstract dimensions of the IT-end user relationship (cf above), in particular the people (participants), have adapted to the changes, and now the relationship can continue with its normal activities. It could, of course, be argued that in the real world a relationship which was disturbed by change, could not be put in a "box of transformation" and when it comes out of that box, everything is again all right. This argument has substance and it is therefore important that the monitoring system is used, so as to evaluate the elements of the physical and abstract dimensions on a continuous basis to ensure that this kind of problem can be managed. In this regard it is important to take note of Ciborra's ( [5], op. cit.) comment about flexibility:

"Flexibility comes in handy: improvisation is deployed to fill the gaps between the unavoidable so-called standard operating procedure and the actual events as they occur in the flow of daily work (referring to Zimmerman (1973); Wynn (1979); Suchman (1983))."

\section{CONCLUDING SUMMARY}

In this paper the elements of the physical and abstract dimensions of an IT-end user relationships were described. It was argued that these two dimensions enable one to fully describe the holistic nature of IT-end user relationships. A conceptual framework is described for the management of IT-end user relationships under circumstances where no change is 
involved. The framework attempts to incorporate and describe all the important soft issues, which were argued to be necessary for the management of an IT-end user relationship environment. It was further argued that if any one of the elements of either the abstract or physical dimension was disturbed in a negative way, it will have a negative impact on the whole relationship. It is therefore important that the change management process should not only concentrate on the transformation of the participants (human beings) but also on rectifying physical elements such as technology and structures that have a negative impact on a relationship.

Thereafter a conceptual framework was proposed for the management of change with respect to the IT-end user relationship environment.

The combined frameworks also serve as a supporting "tool" for managers to obtain a better understanding of the complexities involved in terms of the human side of systems development.

\section{REFERENCES}

[1] Beard Jon W, Peterson Tim O, A Taxonomy for the Study of Human Factors in Management Information Systems (MIS). In Carey M J. 1988: Human factors in management information systems, Ablex Publishing Corporation, USA.

[2] Bommer Michael, Gratto Clarence, Gravander Jerry, Tuttle Mark, A Behaviour Model of Ethical and Unethical Decision Making. In Dejoie Roy, Fowler George, Paradice David, 1991: Ethical Issues in Information Systems. Boyd \& fraser publishing company.

[3] Caperelli David, Management Corner: Leading the company through the chokepoints of change, Information Strategy: The Executive's Journal, Spring 1996, 36-44.

[4] Ciborra, Claudio U (1993): Teams, markets and systems Business Innovation and Information Technology, Cambridge University Press, UK.

[5] Ciborra, Claudio U (1996): Improvisation and Information Technology in Organizations. Proceedings of the Seventeenth International Conference on Information Systems, Cleveland, Ohio, December 16-18, 1996, 369-380.

[6] Clarke, A A \& Smyth, M G G, A co-operative computer based on the principles of human co-operation: International Journal of Man-machine studies, Vol. 38, 1993, 322.

[7] CSC Foundation, 1994: Future roles and responsibilities for the IS Department, Final Report 96.

[8] Dahlbom B, Mathiassen L, 1993: Computers In Context; The philosophy and Practice of Systems Design. Blackwell Publishers, Cambridge UK.

[9] DeSanctis, Poole M S, Capturing the Complexity in Advanced Technology Use: Adaptive Structuration Theory, vol 5, No. 2, May 1994.

[10] Du Plooy NF, Overcoming the culture gap between management and IT staff, Paper delivered at Conference on "HR Management of IT staff", IEC, Jan Smuts, March 1995.

[11] Introna Lucas D, 1994: Giddens, Emergence and Social Intervention. Paper presented at the International Conference on Systems Thinking and Progressive Social Change, University of Cape Town, South Africa, 2-15. 
[12] Kelly, Mark, 1991: The Adventures of a Self-Managing Team, Pfeiffer \& Company, San Diego.

[13] Kinlaw, Dennis C., 1989: Coaching for Commitment: Managerial Strategies for Obtaining Superior Performance, University Associates, Inc.,USA

[14] Leonard AC, 1998: Information Technology-End User Relationship In A Changing Environment, Thesis (D.Com.(Informatics))-University of Pretoria,1998. Unpublished.

[15] Moad Jeff, Does your CEO get it?, Datamation, September 1994.

[16] Newcomb Theodore Mead (1997): Social psychology: the study of human interaction.

[17] Newman Michael \& Sabherwal Rajiv (1996): Determinants of Commitment to Information Systems Development: A Longitudinal Investigation, MIS Quarterly, March 1996, 23-54.

[18] Pheysey, Diana C, 1993: Organizational Cultures, Routledge, New York.

[19] Reich, B,H, Benbasit, Izak. 1999: Factors that influence the social dimension of alignment between business and information technology objectives. By the Society of Information Management (SIM) and the Management Information Systems Research Center (MISRC).

[20] Robey, Daniel \& Sales, Carol A., 1994: Designing Organizations, Richard D. Irwin, Inc., USA

[21] Sprague, Ralph H \& McNurlin, Barbara C, 3rd ed 1993: Information systems management in practice, Prentice Hall, Englewood Cliffs.

[22] Stokes, Stewart L (Jr), A Marketing Orientation for End-User Computing Support. In Umbaugh R E, 1991: Handbook of IS Management (Third Edition), Auerbach Publishers, Boston and New York, 125-134.

[23] Welty B, Becerra-Fernandez, Managing Trust and Commitment in Collaborative: Communications of the ACM, June 2001, 67-73, Vol. 44, No. 6,

[24] Wike W R, Andersen A \& Co., Service management. CMG XV International conference on the management and performance of computer systems: Conference proceedings, p. 534-540, December 1984, San Francisco, USA.

\section{End notes}

${ }^{1}$ As human beings, people are viewed in this regard as the physical enablers who initiate, create, participate and maintain relationships, because of their interaction with one another during transacting. This is in line with the adaptive structuration theory of DeSanctis \& Poole (1994) which is used for theory building in my research; see also Orlikowski (1992) whose structurational model of IT consists of three components, viz, human agents, IT, and institutional properties of organizations.

${ }^{2}$ The term help is used in the context of the citation from Stokes referred to by Cusack (cf above). 